\title{
CRESCIMENTO FÚNGICO E PRODUÇÃO DE LACASES DE Pleurotus sajor-caju PS-2001 EM DIFERENTES CONFIGURAÇÕES DE BIORREATORES SOB EFEITO DO pH
}

\author{
F. BETTIN ${ }^{1}$, F. COUSSEAU ${ }^{1}$, K. MARTINS ${ }^{1}$, S. ZACCARIA $^{1}$, \\ M.M. da SILVEIRA ${ }^{1}$ e A.J.P. DILLON ${ }^{1}$ \\ ${ }^{1}$ Universidade de Caxias do Sul, Instituto de Biotecnologia \\ Laboratório de Enzimas e Biomassas - Laboratório de Bioprocessos \\ E-mail para contato: fbettin@ucs.br
}

\begin{abstract}
RESUMO - Lacases são enzimas que oxidam compostos fenólicos reduzindo o oxigênio a água pela retirada de um elétron do substrato aromático e que apresentam potenciais aplicações ambientais e biotecnológicas. Neste estudo, avaliou-se a cinética de crescimento e a produção de lacases de Pleurotus sajorcaju PS-2001 em biorreatores com agitação mecânica e airlift de circulação interna em valores de $\mathrm{pH}$ fixos em 6,0, 6,5 e 7,0, mantidos durante 90 horas de processo. Em biorreator airlift, atividades de lacases superiores $\left(132 \mathrm{U} . \mathrm{mL}^{-1} \mathrm{em}\right.$ 90 horas) foram observadas com relação ao biorreator mecanicamente agitado (80 U.mL ${ }^{-1}$ em 66 horas); porém, em ambas as condições, o pH mais favorável à produção enzimática foi 6,5 . Os percentuais de saturação em oxigênio dissolvido apresentaram queda nos valores durante o período de intenso metabolismo e crescimento fúngico em todos os experimentos. Para os dois sistemas avaliados, os valores de biomassa micelial nos testes realizados em pH 6,0 e 7,0 (acima de 3 g. $\mathrm{L}^{-1}$ ) foram superiores aos observados em $\mathrm{pH}$ 6,5 (abaixo de 2 g. $\mathrm{L}^{-1}$ ), sugerindo que maior crescimento não se reflete em aumento da síntese enzimática, nas condições testadas. Lacases são as principais enzimas produzidas pelo fungo estudado e sua síntese parece estar relacionada com a geometria e a configuração dos biorreatores, com o pH e com o suprimento de oxigênio durante os processos.
\end{abstract}

\section{INTRODUÇÃO}

Lacases são polifenol-oxidases produzidas pela maioria dos fungos da degradação branca e catalisam a oxidação de uma ampla faixa de aminas fenólicas e aromáticas (Thurston, 1994). Essas enzimas estão envolvidas na degradação da lignina e o uso de sistemas mediados por lacases é uma alternativa promissora para processos biotecnológicos de interesse ambiental, como branqueamento de polpa de celulose, descoloração de corantes têxteis, remoção de fenóis, oxidação de hidrocarbonetos aromáticos policíclicos, detoxificação de efluentes e poluentes ambientais (Canet et al., 2001; Tinoco et al., 2001; Munari et al., 2007; Schmitt et al., 2012).

Diferentes configurações de biorreatores são utilizadas em cultivos submersos, dependendo do microrganismo e do produto desejado. Biorreatores com agitação mecânica se caracterizam pela presença de agitadores e chicanas, elementos que permitem eficiência em 
termos de transferência de calor e de massa, homogeneidade e mistura do sistema, ruptura de bolhas de ar e dispersão de agregados celulares (Schmidell e Facciotti, 2001). No entanto, em cultivos de fungos filamentosos, a exposição a altas frequências dos agitadores pode provocar ruptura do micélio, devido ao alto cisalhamento, gerando redução tanto da biomassa como da síntese enzimática. Biorreatores airlift possibilitam grandes vazões de ar, aumentando a transferência de oxigênio gás-líquido e combinando uma mistura eficiente das fases com baixo cisalhamento; aeração e agitação fornecidas com baixo consumo de energia, simplicidade de configuração e construção, fluxo padrão, baixa potência e boa mistura representam algumas das vantagens de sua aplicação (Lin et al., 2004).

Em processos aeróbios, o crescimento celular eleva a demanda de oxigênio e, simultaneamente, a viscosidade aparente do caldo, o que dificulta a transferência desse gás da fase gasosa para a líquida, reduzindo o coeficiente volumétrico de transferência de oxigênio $\left(\mathrm{K}_{\mathrm{L}} \mathrm{a}\right)$. $\mathrm{O}$ cisalhamento é um importante parâmetro a ser analisado durante a operação de um biorreator, pois quanto maior a frequência dos agitadores, maior será a transferência de oxigênio, que é um fator limitante no processo; no entanto, quanto maior a agitação, maior também será o cisalhamento celular, que pode causar mudanças morfológicas irreversíveis no microrganismo e alterações reológicas no caldo fermentativo, influenciando todo o processo. $\mathrm{O}$ excesso de cisalhamento pode resultar em perda de viabilidade, rompimento celular e, até mesmo, na morte microbiana (Merchuk e Asenjo, 1995; Campesi, 2007).

Em cultivos submersos, fungos filamentosos podem apresentar diferentes morfologias, dependendo do microrganismo e das condições de cultivo. Cultivos em que ocorre a formação de pellets miceliais são particularmente exigentes em termos de transferência de oxigênio, uma função complexa relacionada com parâmetros operacionais, como agitação, vazão de ar e geometria do reator (Ju et al., 1991). O tamanho e a estabilidade dos pellets miceliais, assim como a morfologia fúngica, são afetados pela composição do meio e pelas condições hidrodinâmicas da cultura, como frequência dos agitadores, aeração e viscosidade aparente, interferindo diretamente na produção enzimática. O controle desses parâmetros é importante para prevenir limitações de oxigênio (Márquez-Rocha et al., 1999; Mikiashvili et al., 2006).

O gênero Pleurotus representa um dos cinco fungos comestíveis mais cultivados do mundo, com boa adaptação a diferentes condições de crescimento em culturas líquidas. Pleurotus sajor-caju PS-2001 é um produtor de lacases que apresenta crescimento relativamente rápido em processo submerso, com relevante síntese enzimática (Confortin et al., 2008; Bettin et al., 2009; Bettin et al., 2011). Vários fatores influenciam a produção de lacases fúngicas em culturas submersas, dentre os quais se destacam composição do meio de cultivo, tempo de incubação, inóculo, agitação, aeração, regime de operação, temperatura e pH (Mikiashvili et al., 2006). Diante disso, o objetivo do presente trabalho foi avaliar a cinética de crescimento e a produção de lacases de $P$. sajor-caju PS-2001 em biorreatores com agitação mecânica e airlift de circulação interna sob diferentes condições de $\mathrm{pH}$.

\section{MATERIAL E MÉTODOS}

Linhagem - Pleurotus sajor-caju PS-2001, da coleção de microrganismos do IB-UCS, foi mantido em meio contendo serragem de Pinus spp., $20 \mathrm{~g}$; farelo de trigo, $20 \mathrm{~g}$; $\mathrm{CaCO}_{3}, 2$ g; ágar-ágar, $20 \mathrm{~g} ; \mathrm{H}_{2} \mathrm{O}$ destilada q.s.p. 1 L. As placas com a linhagem foram mantidas em estufa a $28^{\circ} \mathrm{C}$ até completo crescimento micelial e armazenadas a $4^{\circ} \mathrm{C}$ (Bettin et al., 2009). 
Composição da solução mineral - $\mathrm{KH}_{2} \mathrm{PO}_{4}, 20 \mathrm{~g}$; $\left(\mathrm{NH}_{4}\right)_{2} \mathrm{SO}_{4}, 14 \mathrm{~g}$; $\mathrm{CaCl}_{2}, 3 \mathrm{~g}$; $\mathrm{MgSO}_{4} .7 \mathrm{H}_{2} \mathrm{O}, 3 \mathrm{~g}$; ureia, $3 \mathrm{~g} ; \mathrm{MnSO}_{4} \cdot \mathrm{H}_{2} \mathrm{O}, 15,6 \mathrm{mg} ; \mathrm{FeSO}_{4}, 50 \mathrm{mg} ; \mathrm{ZnSO}_{4}, 14 \mathrm{mg}$; $\mathrm{CoCl}_{2}$, $20 \mathrm{mg} ; \mathrm{H}_{2} \mathrm{O}$ destilada q.s.p. 1 L (Mandels e Reese, 1957).

Inóculos - Preparados em frascos Erlenmeyer de $500 \mathrm{~mL}$ contendo $100 \mathrm{~mL}$ de meio composto por: glicose, $5 \mathrm{~g}$; caseína pura, $1,5 \mathrm{~g}$; solução mineral de nutrientes e micronutrientes, $100 \mathrm{~mL} ; \mathrm{H}_{2} \mathrm{O}$ destilada q.s.p. 1 L. Após autoclavagem, três discos de ágar de $1,5 \mathrm{~cm}$ de diâmetro foram raspados de placas com a linhagem e acrescentados ao meio (Bettin et al., 2009). O crescimento ocorreu sob agitação recíproca por 6 dias, a $180 \mathrm{rpm} \mathrm{e} 28 \pm 2^{\circ} \mathrm{C}$. A proporção dos inóculos para os cultivos em biorreatores foi de 10\% (v/v) (Bettin et al., 2011).

Meios de cultivo fúngico em biorreatores - A composição dos meios foi baseada em glicose, $5 \mathrm{~g}$; caseína pura, 1,5 g; ácido benzoico, $122 \mathrm{mg}$; $\mathrm{CuSO}_{4}, 100 \mathrm{mg}$; solução mineral de nutrientes e micronutrientes, $100 \mathrm{~mL} ; \mathrm{H}_{2} \mathrm{O}$ destilada q.s.p. 1 L. Os meios foram autoclavados por 20 minutos, juntamente com as cubas dos biorreatores. Em todas as condições, antiespumante à base de silicone foi adicionado, quando necessário (Bettin et al., 2011).

Condições de cultivo em biorreator com agitação mecânica - Foi utilizado um biorreator B. Braun, modelo Biostat ${ }^{\circledR} \mathrm{B}$, com volume nominal de $5 \mathrm{~L}$ e operacional de $4 \mathrm{~L}$. As condições iniciais (200 rpm e $2 \mathrm{~L} \cdot \mathrm{min}^{-1} \mathrm{de}$ ar - 0,5 vvm) foram fixadas nas primeiras horas de cultivo e mantidas até níveis mínimos de cerca de 30\% da saturação em oxigênio dissolvido (OD). Foram utilizadas três turbinas de pás planas durante os experimentos e o coeficiente volumétrico de transferência de oxigênio $\left(\mathrm{k}_{\mathrm{L}} \mathrm{a}\right)$, antes da inoculação, foi de $12 \mathrm{~h}^{-1}$. Os ensaios foram conduzidos em regime descontínuo, $\mathrm{pH} 6,5$ a $28 \pm 1^{\circ} \mathrm{C}$, durante 90 horas.

Condições de cultivo em biorreator airlift de circulação interna - Utilizou-se um biorreator airlift com volume nominal de $6 \mathrm{~L}$ e operacional de $5 \mathrm{~L}$ com dimensões de $75 \mathrm{~cm}$ de altura e $11 \mathrm{~cm}$ de diâmetro; o tubo interno (riser) possui $34 \mathrm{~cm}$ de altura e $7 \mathrm{~cm}$ de diâmetro. A vazão de ar (1 L.min ${ }^{-1}$ de ar - 0,2 vvm) não foi alterada durante o processo em todos os experimentos realizados, com percentual de saturação em OD flutuando livremente; o $\mathrm{k}_{\mathrm{L}} \mathrm{a}$ antes da inoculação foi de $34 \mathrm{~h}^{-1}$. Os testes em airlift também foram conduzidos em regime descontínuo, $\mathrm{pH} 6,5$ a $28 \pm 1{ }^{\circ} \mathrm{C}$, durante 90 horas.

Atividade de lacases - Lacases foram quantificadas pela oxidação do substrato ABTS em tampão acetato de sódio pH 5,0 durante 90 segundos a $25^{\circ} \mathrm{C}$ (Wolfenden e Willson, 1982).

Determinação das concentrações de substrato e de biomassa fúngica - $\mathrm{O}$ consumo do substrato (glicose) utilizado nos cultivos foi quantificado com a utilização do reagente DNS (ácido 3,5-dinitrosalicílico) e curva padrão de glicose, de acordo com Miller (1959). A concentração celular foi mensurada por gravimetria, em cadinhos de porcelana.

\section{RESULTADOS E DISCUSSÃO}

Os dados deste trabalho se referem a ensaios conduzidos em diferentes configurações de biorreatores em regime descontínuo utilizando valores de $\mathrm{pH}$ fixos em 6,0, 6,5 e 7,0. Em todas as condições testadas, buscou-se avaliar a síntese de lacases de P. sajor-caju PS-2001, assim como as cinéticas de crescimento e os consumos de substrato e de oxigênio dissolvido, durante 90 horas de processo. Na Figura 1, os perfis de produção de lacases mostram que, em pH 6,5 obtiveram-se as mais elevadas atividades enzimáticas, tanto em biorreator com agitação mecânica (Figura 1A) como em airlift (Figura 1B), atingindo picos de 80 e 132 
U.mL $L^{-1}$, respectivamente. No reator mecanicamente agitado, as atividades máximas dessas enzimas em pH 6,0 e 7,0 foram inferiores a $20 \mathrm{U}_{\mathrm{mL}}^{-1}$, enquanto que, em airlift, os níveis enzimáticos para esses mesmos valores de $\mathrm{pH}$ foram mais elevados (acima de $60 \mathrm{U} \cdot \mathrm{mL}^{-1}$ ).
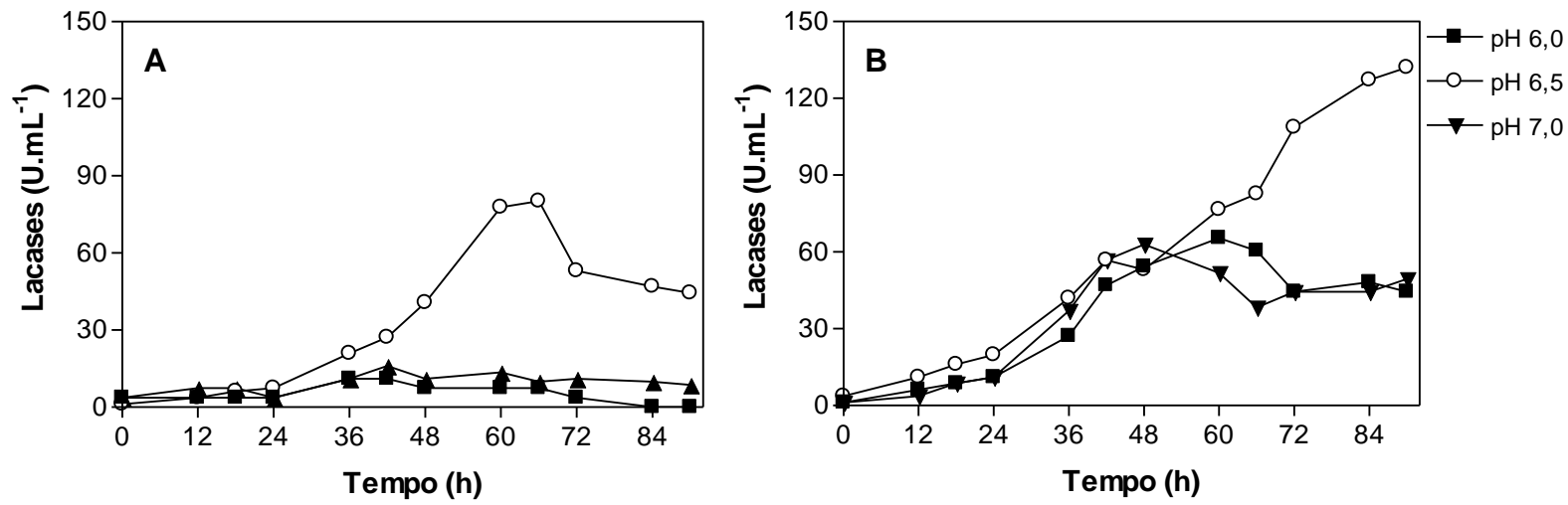

Figura 1 - Atividades de lacases em função do tempo obtidas durante cultivos submersos de

Pleurotus sajor-caju PS-2001 realizados em biorreatores com agitação mecânica (A) e airlift de circulação interna (B) sob diferentes valores de $\mathrm{pH}$ a $28^{\circ} \mathrm{C}$.

O consumo de oxigênio dissolvido (OD) para os dois sistemas avaliados é apresentado na Figura 2. Em biorreator com agitação mecânica (Figura 2A), os percentuais de saturação foram mantidos em níveis mínimos de $30 \%$ apenas pela variação na vazão de ar, sem alteração da frequência dos agitadores inicial $(200 \mathrm{rpm})$; em pH 6,5, observou-se um período mais longo com relação aos valores de 6,0 e 7,0 (cerca de 48 horas) para o que os níveis de OD começassem a decrescer. Em airlift (Figura 2B), a aeração inicial (1 L.min ${ }^{-1}$ ) foi mantida durante todo o processo; assim, em $\mathrm{pH}$ 6,0 e 6,5, os níveis de OD foram próximos a zero a partir de 66 horas de cultivo, com níveis mínimos de 54\% em pH 7,0.
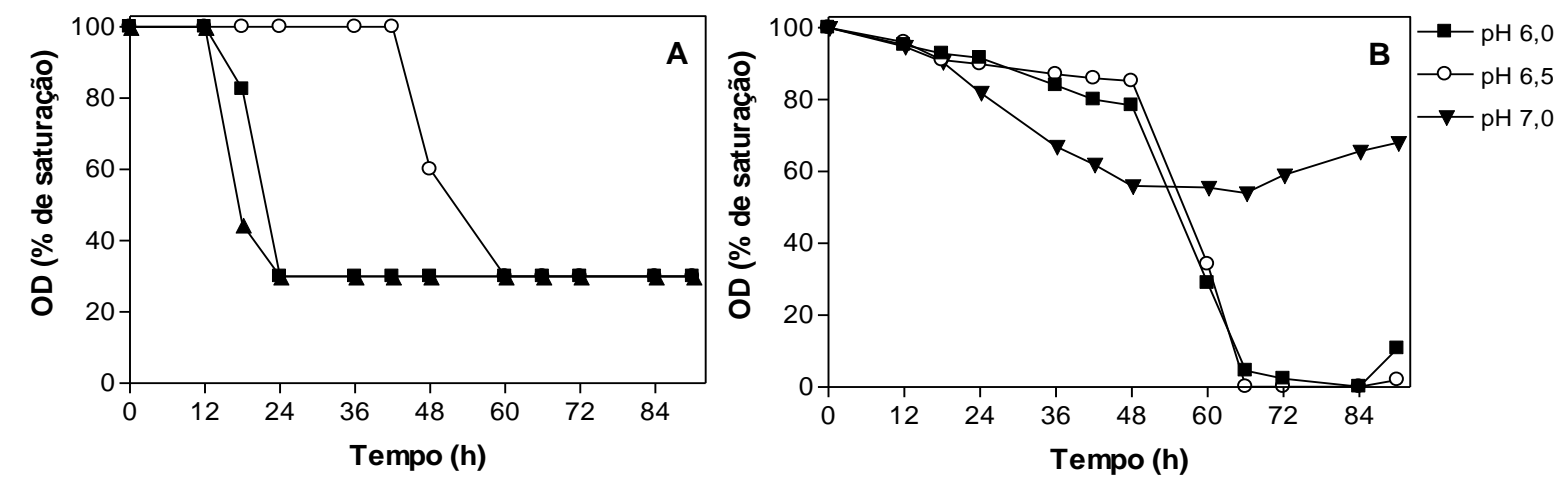

Figura 2 - Consumo de oxigênio dissolvido (OD) em função do tempo durante cultivos submersos de Pleurotus sajor-caju PS-2001 realizados em biorreatores com agitação mecânica (A) e airlift de circulação interna (B) sob diferentes valores de $\mathrm{pH}$ a $28^{\circ} \mathrm{C}$.

Liu et al. (2013), em cultivos submersos realizados em biorreator airlift de 65 L, mostraram que lacases são as principais enzimas produzidas por Pycnoporus sp., evidenciando alto acúmulo de biomassa nos primeiros dias de cultivo e decréscimo nos níveis de $\mathrm{pH}$ e de oxigênio dissolvido, assim como observado para $P$. sajor-caju PS-2001 (Figura 2).

Na Figura 3, são apresentados os dados referentes ao consumo de substrato e à concentração de biomassa. De uma forma geral, observa-se que, para os dois tipos de 
biorreatores, o crescimento micelial foi superior em valores de $\mathrm{pH}$ de 6,0 e 7,0 (Figuras 3A, 3B, 3E e 3F), superiores a 3 g.L $L^{-1}$. Já em pH 6,5 (Figuras 3C e 3D) a biomassa foi inferior a 2 g. $\mathrm{L}^{-1}$ tanto em biorreator com agitação mecânica como em airlift; porém, nesse valor de $\mathrm{pH}$ foram observadas as atividades de lacases mais elevadas (Figura 1). Com relação ao consumo de substrato, níveis residuais inferiores a 1 g. $\mathrm{L}^{-1}$ foram observados em todas as condições testadas no final dos processos, em 90 horas de cultivo, indicando que glicose foi uma fonte de carbono eficiente para o crescimento fúngico, nas condições testadas.
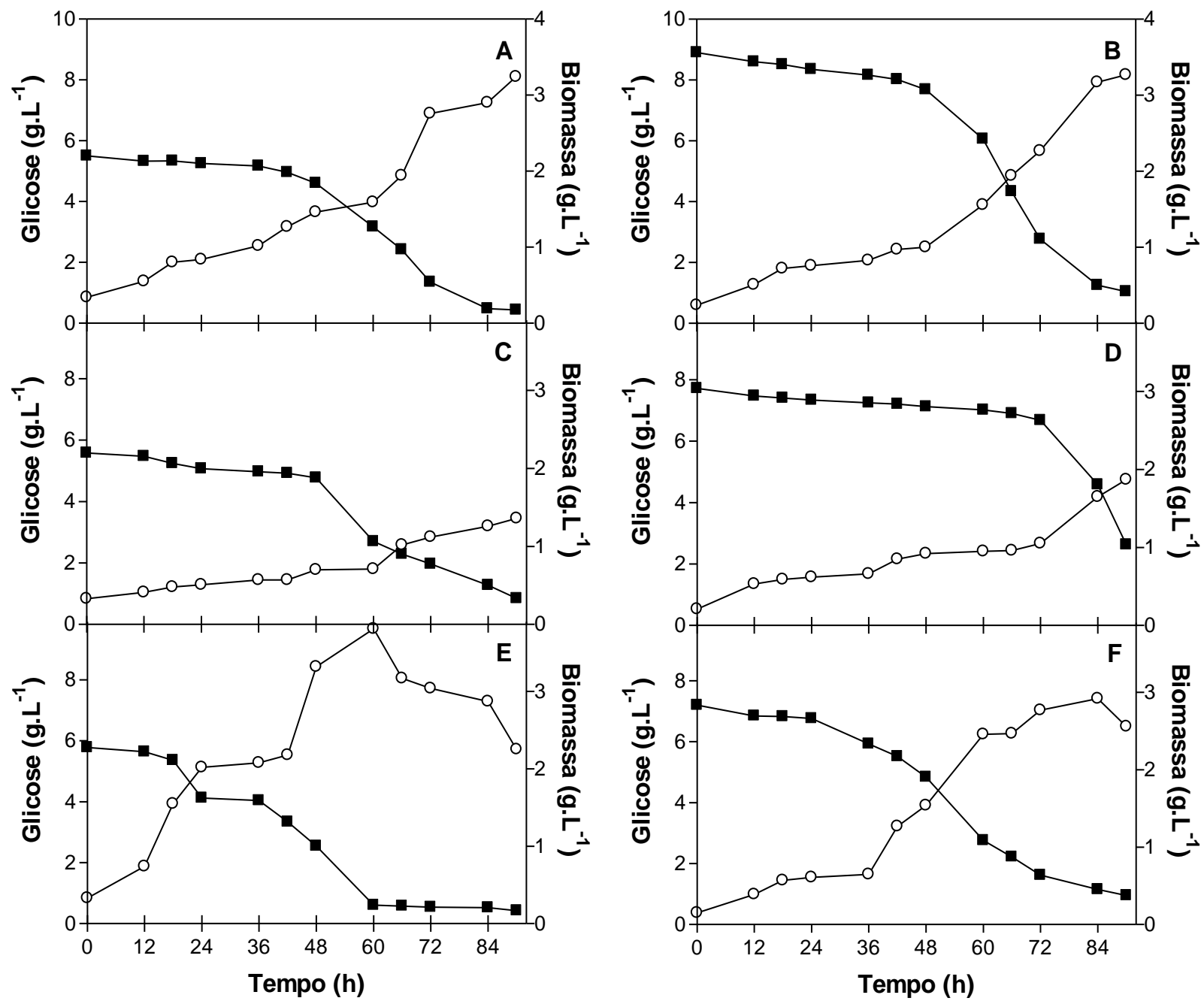

Figura 3 - Consumo de substrato (-口-) e concentração de biomassa (-O-) em função do tempo durante cultivos submersos de Pleurotus sajor-caju PS-2001 realizados em biorreatores com agitação mecânica (A, C e E) e airlift de circulação interna (B, D e F) a $28^{\circ} \mathrm{C}$ em pH 6,0 (A e B), pH 6,5 (C e D) e pH 7,0 (E e F).

Na Tabela 1, estão resumidos os principais resultados gerais obtidos nos cultivos. Os dados referentes à enzima $\left(\mathrm{Y}_{\mathrm{E} / \mathrm{S}}\right.$ e $\left.\mathrm{P}_{\mathrm{E}}\right)$ correspondem ao tempo em que foi detectado o pico de atividade de lacases $\left(\mathrm{Lac}_{\text {máx }}\right)$, enquanto os dados referentes à biomassa $\left(\mathrm{Y}_{\mathrm{X} / \mathrm{S}} \mathrm{e} \mathrm{P}_{\mathrm{X}}\right)$ correspondem ao tempo em que foi observado o pico de concentração celular $\left(\mathrm{X}_{\text {máx }}\right)$; o fator de rendimento específico $\left(\mathrm{Y}_{\mathrm{E} / \mathrm{X}}\right)$ relaciona a máxima atividade de lacases com a máxima concentração celular. A produtividade volumétrica $\left(\mathrm{P}_{\mathrm{E}}\right)$ foi superior a $1 \mathrm{U} \cdot \mathrm{mL}^{-1} \cdot \mathrm{h}^{-1} \mathrm{em}$ todos 
os testes realizados em airlift, que também mostraram atividades enzimáticas mais elevadas comparando-se os dois sistemas em todos os valores de $\mathrm{pH}$ testados; em biorreator com agitação mecânica, somente em pH 6,5 produtividade enzimática semelhante foi observada. Esses dados sugerem que processos realizados em biorreator airlift são mais eficientes para a produção de lacases, nas condições avaliadas. Com relação ao rendimento enzimático $\left(\mathrm{Y}_{\mathrm{E} / \mathrm{S}}\right)$, resultados semelhantes foram observados em todos os experimentos, com exceção de $\mathrm{pH} 7,0$ em biorreator com agitação mecânica, que mostrou valores inferiores. A produtividade $\left(\mathrm{P}_{\mathrm{X}}\right)$ e o rendimento $\left(\mathrm{Y}_{\mathrm{X} / \mathrm{S}}\right)$ celulares foram mais baixos em $\mathrm{pH}$ 6,5 para ambos os sistemas avaliados, o que está relacionado com o crescimento inferior observado nesse valor de $\mathrm{pH}$. Os dados de fator de rendimento específico $\left(\mathrm{Y}_{\mathrm{E} / \mathrm{X}}\right)$ mostram que a relação entre síntese de lacases e formação de biomassa foi superior em $\mathrm{pH}$ 6,5, pois além de elevados títulos enzimáticos, o crescimento nessas condições foi mais baixo com relação os valores de pH de 6,0 e 7,0.

Tabela 1 - Resultados gerais obtidos durante cultivos submersos de Pleurotus sajor-caju PS-2001 realizados em biorreatores com agitação mecânica e airlift de circulação interna sob diferentes valores de $\mathrm{pH}$ a $28^{\circ} \mathrm{C}$

\begin{tabular}{|c|c|c|c|c|c|c|}
\hline \multirow{3}{*}{ PARÂMETROS } & \multirow{2}{*}{\multicolumn{3}{|c|}{$\frac{\text { Biorreator com agitação mecânica }}{\text { pH }}$}} & \multirow{2}{*}{\multicolumn{3}{|c|}{$\frac{\text { Biorreator airlift }}{\mathrm{pH}}$}} \\
\hline & & & & & & \\
\hline & 6,0 & 6,5 & $\mathbf{7 , 0}$ & 6,0 & 6,5 & $\mathbf{7 , 0}$ \\
\hline $\operatorname{Lac}\left(\right.$ U.mL $\left.{ }^{-1}\right)$ & 11,1 & 80,2 & 16,0 & 65,4 & 132,1 & 63,0 \\
\hline Tempo (h) & 36 & 66 & 42 & 60 & 90 & 48 \\
\hline$P_{E}\left(U \cdot m L^{-1} \cdot h^{-1}\right)$ & 0,206 & 1,197 & 0,294 & 1,070 & 1,427 & 1,286 \\
\hline$Y_{E / S}\left(U_{\cdot} g^{-1}\right)$ & 22663 & 24029 & 5064 & 22604 & 25210 & 26188 \\
\hline$X_{\text {máx }}\left(\right.$ g.L $\left.L^{-1}\right)$ & 3,24 & 1,36 & 3,81 & 3,27 & 1,87 & 2,92 \\
\hline Tempo (h) & 90 & 90 & 60 & 90 & 90 & 84 \\
\hline$P_{X}\left(g \cdot L^{-1} \cdot h^{-1}\right)$ & 0,032 & 0,011 & 0,058 & 0,034 & 0,018 & 0,033 \\
\hline$Y_{X / S}\left(g \cdot g^{-1}\right)$ & 0,573 & 0,285 & 0,673 & 0,385 & 0,326 & 0,458 \\
\hline$Y_{E / X}\left(U_{. g}{ }^{-1}\right)$ & 3,426 & 58,970 & 4,199 & 20,000 & 70,641 & 21,575 \\
\hline
\end{tabular}

Legenda: $\mathbf{L a c}_{\text {máx }}$ (máxima atividade de lacases), $\mathbf{P}_{\mathbf{E}}$ (produtividade volumétrica de lacases), $\mathbf{Y}_{\mathbf{E} / \mathbf{S}}$ (fator de rendimento de substrato em atividade de lacases), $\mathbf{X}_{\text {máx }}$ (máxima concentração celular), $\mathbf{P}_{\mathbf{X}}$ (produtividade volumétrica de biomassa), $\mathbf{Y}_{\mathbf{X} / \mathbf{S}}$ (fator de rendimento de substrato em células), $\mathbf{Y}_{\mathbf{E} / \mathbf{X}}$ (fator de rendimento específico relacionando a máxima atividade de lacases com a máxima concentração celular).

As atividades de lacases superiores obtidas em airlift com relação ao biorreator com agitação mecânica (Figura 1), nos diferentes valores de $\mathrm{pH}$ testados, podem estar relacionadas às diferentes configurações, dimensões e geometrias que esses sistemas apresentam. Contudo, outro fator que pode ter influenciado nessa diferença é o suprimento de oxigênio, visto que, nesses ensaios, utilizaram-se volumes operacionais, aerações, $\mathrm{k}_{\mathrm{L}} \mathrm{a}$ inicial e percentuais mínimos de saturação em OD diferentes (Figura 2), dificultando uma análise comparativa mais precisa entre os dois sistemas. Além disso, embora não tenha sido avaliado por meio de microscopia, sugere-se que o baixo cisalhamento micelial proporcionado pelo biorreator airlift também possa ter beneficiado a produção de lacases de P. sajor-caju PS-2001 neste sistema, pois a morfologia dos pellets variou entre diâmetros de cerca de 0,5-1,0 cm em airlift e abaixo de $0,5 \mathrm{~cm}$ em biorreator com agitação mecânica. Ainda, a viscosidade aparente do caldo pareceu ser ligeiramente maior no sistema mecanicamente agitado, o que pode ter sido ocasionado pela presença de turbinas, ausentes no sistema airlift. 
Os dados obtidos nesse trabalho corroboram os obtidos por Rancaño et al. (2003), que estudaram a produção de lacases por Trametes versicolor em biorreator airlift, observando que a configuração do biorreator foi apropriada para a obtenção de elevadas atividades enzimáticas e, também, para a descoloração do corante vermelho de fenol. Aleksieva e Peeva (2000) avaliaram a produção de proteinase ácida pelo fungo filamentoso Humicola lutea em biorreatores com agitação mecânica e airlift, observando que o desempenho do processo foi semelhante em ambos os sistemas de cultivo com relação à utilização do substrato, formação de biomassa, variação do $\mathrm{pH}$ e concentração de enzimas. Entretanto, atividades de poligalacturonases de Aspergillus oryzae foram ligeiramente superiores em cultivos realizados em biorreator com agitação mecânica em comparação com airlift (Fontana et al., 2009), diferentemente do que foi observado para P. sajor-caju PS-2001.

\section{CONCLUSÕES}

Os resultados obtidos mostram que o $\mathrm{pH}$ influencia tanto a produção enzimática quanto o crescimento fúngico de $P$. sajor-caju PS-2001 em diferentes configurações de biorreatores. Nas condições avaliadas, $\mathrm{pH}$ 6,5 favorece a síntese de lacases tanto em biorreator com agitação mecânica como em airlift; porém, valores de $\mathrm{pH}$ de 6,0 e 7,0 promovem maiores concentrações de biomassa micelial. Comparando-se as atividades obtidas nos dois sistemas, airlift parece ser mais adequado para a produção de lacases com relação ao biorreator mecanicamente agitado. Em continuidade, outros estudos estão sendo desenvolvidos para elucidar os efeitos da ampla gama de fatores que influenciam a atividade enzimática e o crescimento fúngico nestes e em outros sistemas de cultivo.

\section{REFERÊNCIAS}

ALEKSIEVA, P.; PEEVA, L. Investigation of acid proteinase biosynthesis by the fungus Humicola lutea 120-5 in an airlift bioreactor. Enzyme Microb. Technol., v. 26, p. 402-405, 2000.

BETTIN, F.; MONTANARI, Q.; CALlONI, R.; GAIO, T.A.; SILVEIRA, M.M.; DILLON, A.J.P. Production of laccases in submerged process by Pleurotus sajor-caju PS-2001 in relation to carbon and organic nitrogen sources, antifoams and Tween 80. J. Ind. Microbiol. Biotechnol., v. 36, p. 1-9, 2009.

BETTIN, F.; ROSA, L.O.; MONTANARI, Q.; CALLONI, R.; GAIO, T.A.; MALVESSI, E.; SILVEIRA, M.M.; DILLON, A.J.P. Growth, kinetics, production, and characterization of extracellular laccases from Pleurotus sajor-caju PS-2001. Process Biochem., v. 46, p. 758-764, 2011.

CAMPESI, A. Avaliação da velocidade de cisalhamento média em biorreator convencional tipo tanque agitado e aerado. Dissertação de Mestrado. São Carlos: Universidade Federal de São Carlos, Brasil, 2007.

CANET, R.; BIRNSTINGL, J.G.; MALCOLM, D.G.; LOPEZ-REAL, J.M.; BECK, A.J. Biodegradation of polycyclic aromatic hydrocarbons (PAHs) by native microflora and combinations of white-rot fungi in a coal-tar combinated soil. Bioresour. Technol., v. 76, p. 113$117,2001$.

CONFORTIN, F.G.; MARCHETTO; R.; BETTIN, F.; CAMASSOLA, M.; SALVADOR, M.; DILLON, A.J.P. Production of Pleurotus sajor-caju strain PS-2001 biomass in submerged culture. J. Ind. Microbiol. Biotechnol., v. 35, p. 1149-1155, 2008. 
FONTANA, R.C.; POLIDORO, T.A.; SILVEIRA, M.M. Comparison of stirred tank and airlift bioreactors in the production of polygalacturonases by Aspergillus oryzae. Bioresour. Technol., v. 100, p. 4493-4498, 2009.

JU, L.K.; HO, C.S.; SHANADAN, J.F. Effects of carbon dioxide on the rheological behavior and oxygen transfer in submerged penicillin fermentations. Biotechnol. Bioeng., v. 38, p. 1223-1232, 1991.

LIN, J.; HAN, M.; WANG, T.; ZHANG, T.; WANG, J.; JIN, Y. Influence of the gas distributor on the local hydrodynamic behavior of an external loop airlift reactor. Chem. Eng. J., v. 102, p. 51-59, 2004.

LIU, J.; CAI, Y.; LIAO, X.; HUANG, Q.; HAO, Z.; HU, M.; ZHANG, D.; LI, Z. Efficiency of laccase production in a 65 -L air-lift reactor for potential green industrial and environmental application. $J$. Cleaner Production, v. 39, p. 154-160, 2013.

MANDELS, M.; REESE, E.T. Induction of cellulase in Trichoderma viride as influenced by carbon source and metals. J. Bacteriol., v. 73, p. 269-278, 1957.

MÁRQUEZ-ROCHA, F.J.; GUILLÉN, G.K.; SÁNCHEZ, J.E.; VÁZQUEZ-DUHALT, R. Growth characteristics of Pleurotus ostreatus in bioreactors. Biotechnol. Tech., v. 13, p. 29-32, 1999.

MERCHUK, J.C.; ASENJO, J.A. Fundamentals of bioreactor design. Bioprocess Technol., v. 21, p. 139-205, 1995.

MIKIASHVILI, N.; WASSER, S.P.; NEVO, E.; ELISASHVILI, V. Effects of carbon and nitrogen sources on Pleurotus ostreatus ligninolytic enzyme activity. World J. Microbiol. Biotechnol., v. 22, p. 999-1002, 2006.

MILLER, G.L. Use of dinitrosalicilic acid reagent for determination of reducing sugar. Anal. Chem., v. 31, p. 426-428, 1959.

MUNARI, F.M.; GAIO, T.A.; DILLON, A.J.P. Phenol degradation and colour removal in submerged culture of Pleurotus sajor-caju with paper mill effluents. Biocatal. Biotransform., v. 25, p. 24-28, 2007.

RANCAÑO, G.; LORENZO, M.; MOLARES, N.; COUTO, S.R.; SANROMÁN, M.A. (2003). Production of laccase by Trametes versicolor in an airlift fermentor. Process Biochem., v. 39, p. 467-473, 2003.

SCHMIDELL, W.; FACCIOTTI, M.C.R. Biorreatores e processos fermentativos. In: SCHMIDELL, W.; LIMA, U.A.; AQUARONE, E.; BORZANI, W. (Coord.). Biotecnologia industrial: Engenharia bioquímica. Vol. 2. São Paulo: Edgard Blücher, pp. 179-192, 2001.

SCHMITT, S.; SOUZA, R.; BETTIN, F.; DILLON, A.J.P.; VALLE, J.A.B.; ANDREAUS, J. Decolorization of aqueous solutions of disperse textile dyes by oxidoreductases. Biocatal. Biotransform., v. 30, p. 48-56, 2012.

THURSTON, C.F. The structure and function of fungal laccases. Microbiol., v. 140, p. 19-26, 1994.

TINOCO, R.; PICKARD, M.A.; VAZQUEZ-DUHALT, R. Kinetic differences of purified laccases from six Pleurotus ostreatus strains. Lett. Appl. Microbiol., v. 32, p. 331-335, 2001.

WOLFENDEN, B.S.; WILLSON, R.L. Radical-cations as reference chromogens in the kinetic studies of one-electron transfer reactions: pulse radiolysis studies of 2,2'-azinobis-(3-ethylbenzthiazoline6-sulphonate). J. Chem. Soc. Perkin Trans. II, v. 02, p. 805-812, 1982.

Apoio: FAPERGS, CAPES, CNPq e UCS. 